\title{
Ki-67 immunohistochemical expression in mandibular ameloblastoma: A prognostic indicator for local recurrence
}

\author{
Ayman Hegab $^{1 * \#}$, Mohmmad Shuman ${ }^{2 \dagger}$, Mohammed Abd El-Akher ${ }^{1 \#}$, Delaram Arwlan ${ }^{3}$ \\ ${ }^{1}$ Oral and Maxillofacial Surgery, Faculty of Dental Medicine, Al-Azhar University, Cairo, Egypt \\ ${ }^{2}$ Oral and Maxillofacial Surgery, Faculty of Dental Medicine, Al-Azhar University, Assuit, Egypt \\ ${ }^{3}$ Medcal City Teaching Hospital, Teaching Laboratory, Baghdad, Iraq \\ Email: ${ }^{*}$ hegab@mail.com
}

Received 12 September 2013; revised 12 November 2013; accepted 29 November 2013

Copyright (C) 2013 Ayman Hegab et al. This is an open access article distributed under the Creative Commons Attribution License, which permits unrestricted use, distribution, and reproduction in any medium, provided the original work is properly cited.

\begin{abstract}
Objective: This study used Ki-67 to evaluate the proliferative activity of ameloblastoma in an attempt to provide a scientific basis for any differences in the biologic behaviour that exists between the different types of ameloblastoma and correlate the results with the recurrence rate. Study design: We assessed Ki-67 expression by immunohistochemistry in 32 cases of mandibular ameloblastoma. Formalin-fixed, paraffinembedded blocks were sectioned and used for Haematoxylin \& Eosin (H\&E) staining. H\&E slides were used to re-evaluate the histological types of the ameloblastoma. Immunohistochemical analysis for Ki-67 with a labelled streptavidin-biotin-peroxidase complex technique was performed on tumour sections using Monoclonal Mouse Anti-Human Ki-67 Antigen (clones MIB1, code M7240, Dako Corporation). Lymph nodes (lymphoma) were used as positive control for Ki-67. Results: The specimens comprised 18 cases of Follicular ameloblastoma, 7 cases of Cystic ameloblastoma, 4 cases of plexiform ameloblastoma, and 3 cases of Acanthotic ameloblastoma. The results showed that cellular proliferative activity varied within the ameloblastoma types. There was no statistically significant difference in the Ki-67 Acanthotic, cystic and follicular types of ameloblastoma, while plexiform type showed statistically significantly higher levels than the other 3 types. The mean Ki-67 labelling index of plexiform ameloblastoma ranged from 13 to 30 with a mean of 19.75. The mean values of Ki-67 were statistically significantly higher in recurrent than

${ }^{*}$ Corresponding author.

\#Associate Professors of Oral and Maxillofacial Surgery, Faculty of Dental Medicine, Al-Azhar University, Cairo, Egypt.

${ }^{\dagger}$ Lecturer of Oral and Maxillofacial Surgery, Faculty of Dental Medicine, Al-Azhar University, Assuit, Egypt.
\end{abstract}

non-recurrent cases. Conclusion: The significant expression of Ki-67 could provide useful prognostic markers for proliferative activity and good prognostic indicators for recurrence rate of mandibular ameloblastoma.

Keywords: Mandibular Ameloblastoma; Recurrence; Immunohistochemistry; Ki-67

\section{INTRODUCTION}

Ameloblastoma is a Benign Tumour of Odontogenic epithelium with mature fibrous stroma without odontogenic ectomesenchyme. In the updated World Health Organization (WHO) classification, it was classified into solid/multicystic type, extra-osseous/peripheral type, desmoplastic type and unicystic type [1].

Histologically, there are two main patterns, follicular and plexiform, in which various cellular changes such as squamous metaplasia and granular transformation are commonly seen, and when these are extensive, the terms acanthomatous type and granular cell type are applied, respectively. Cyst formation within the epithelial islands of the follicular type is common. Other rare histological variants, including basal cell ameloblastoma, desmoplastic ameloblastoma and kerato ameloblastoma, have also been described. Despite numerous studies, correlation between these histological patterns and tumour behaviour has not been consistently established [2]. The mechanisms of oncogenesis, cytodifferentiation and tumour progression of ameloblastoma are still largely unknown $[3,4]$.

Determination of epithelial proliferative activity is apotentially useful means of investigating differences inbiologic behaviour between tumours [5-7]. Assessment 
of cell proliferation in many types of tumours is an importent adjunct to histologically based tumour classification and has potential relevance as an indicator of tumour-behaviour and treatment response and relapse. Immunohistochemical assessment of cell proliferation has advantages over the other techniques, such as tritiatedthymidine incorporation and flow cytometry; because the tissue architecture remains intact and proliferating cells can be visualized in relation to other histologic characteristics [8]. The interpretation, merits, and clinical value of the methods of proliferation assessment in tumours are detailed by van Diest et al. [9].

The Ki-67 antigen, which is coded by a geneon chromosome 10, is expressed in the G1, S, and G2 phases in cycling cells $[10,11]$. The Ki-67 score partly correlates with other proliferation markers like $\%$ S-phase cells, and mitotic count [12-15]. Originally, the Ki-67 antigen could only be studied in frozen sections. Recently, a series of Ki-67 antibodies has been developed by the Kiel group that also works on paraffin embedded tumour material after antigen retrieval $[10,11]$. The Ki-67 labelling index was found to be prognostically relevant in several studies [16,17].

The aim of the present study is to evaluate the Ki-67 labelled index in different histologic types of mandibular ameloblastoma and their relation to proliferative activity and local recurrence.

\section{MATERIAL AND METHODS}

\subsection{Patients and Tissue Selection}

A retrospective study of patients who underwent treatment for mandibular ameloblastoma at Al-Azhar University Hospital, Cairo, Egypt from 2001 to 2009 was performed. The study approved by the institutional ethics committee and written informed consent was obtained. Thirty two formalin-fixed, paraffin-embedded archival biopsy specimens were randomly obtained from the Department of Oral and Maxillo facial Surgery at Al-Azhar University Hospital. Patient's files were reviewed to retrieve clinical data, pathology reports, surgical treatment, clinical follow-up and recurrence. All histologic slides were re-evaluated, applying the criteria of the World Health Organization for histological typing of ameloblastoma.

\subsection{Histopathology and Immunohistochemistry}

Formalin-fixed, paraffin-embedded blocks were sectioned (3 - $4 \mu \mathrm{m}$ in thickness) and used for Haematoxylin \& Eosin (H\&E) staining. H\&E slides were used to reevaluate the histological types and characteristics of the ameloblastoma.

The paraffin-embedded tissue sections were also used for Immunohistochemical staining for the antigens Ki-67. Sectioning: 3 - 4 micrometer section is done on the par- affin block on special glass slide and put in oven on 56 degree.

Deparaffinization with xyline and dehydrated with decreasing grades of ethanol alcohol. Demasking of the antigen: Pre-treatment of formalin-fixed, paraffin-embedded tissue sections with heat-induced epitope retrieval (HIER) is required for 20 minutes.

Immunohistochemical analysis for $\mathrm{Ki}-67$ with a labelled streptavidin-biotin-peroxidase complex technique was performed on tumour sections using Monoclonal Mouse Anti-Human Ki-67 Antigen (clone MIB1, code M7240, Dako Corporation) is used at a dilution range of (1:75 - 1:150) for 20 minute at room temperature.

Visualization: The recommended visualization system is Peroxidase/DAB+, Rabbit/Mouse using 20 minutes incubation at room temperature.

- Proper positive and negative controls were performed. Lymphnodes (lymphoma) were used as positive control for Ki-67 and using 20 minutes heat-induced epitope retrieval in Target Retrieval Solution, and 20 minutes incubation at room temperature with the Primary antibody.

- The recommended negative control is Dako Mouse IgG1, diluted to the same mouse.

IgG concentration as the primary antibody.

\subsubsection{Interpretation}

Slides were scanned by $\times 40$ magnification. Ten cellular are as selected (i.e. the so-called hot spots) and evaluated at $\times 400$ magnification. Staining is seen as a dark brown to black nuclear signal in cells expressing the Ki-67 antigen. $\mathrm{Ki}-67$ is expressed in all phases of the cell cycle and is therefore considered a marker of proliferating cells.

$\mathrm{Ki}-67$ proliferation index is assessed by point counting and reported as percent positive.

\subsubsection{Assessment of $\mathrm{Ki}-67$}

Ki-67 labelling index was done by calculating the ratio of positive nuclei in relation to total number of neoplastic nuclei in 10 HPFs. The labelling index (number of positive tumour cells/total number of tumour cells expressed as a percentage) was calculated in every specimen.

\subsection{Statistical Analysis}

Microstat7 for windows statistical package (Microstat Co.) was used for statistical analysis of this study. OneWay ANOVA was used to evaluate the mean values of the Ki-67 in different types of ameloblastoma while independent " $t$ " test was used to compare Ki-67 levels in recurrent and non-recurrent cases.

Difference between mean values was considered statistically significant when $\mathrm{p} \leq 0.05$. 


\section{RESULTS}

This study was carried out on retrospective 32 cases of mandibular ameloblastoma treated in oral and maxillofacial surgery department-Al-Azhar university hospital from the period from 2001 to Jan. 2009 with follow up period until 2011. The male: female ratio was 3:1, with $24(75 \%)$ males and $8(25 \%)$ females. Age distribution ranged from 21 to 78 years, with a mean age of 35.7 years. Most of the cases occurred in the second and third decades of life. The specimens comprised 18 cases of Follicular ameloblastoma (56.2\%), 7 cases of Cystic ameloblastoma (21.8\%), 4 cases of Plexiform ameloblastoma (12.5\%), and 3 cases of Acanthotic ameloblastoma
(9.4\%). Tumours were predominantly located in the molar-angle and angle-ramus regions of the mandible (Table 1).

Recurrence of the ameloblastoma occurred in 8 cases out of 32. The recurrence was higher in male more than female.

4 cases of the recurrence were plexiform ameloblastoma $(100 \%)$ and the other 4 cases occurred in the Follicular ameloblastoma (22\%).

The results showed that cellular proliferative activity varied within the ameloblastoma types. There was no statistically significant difference in the Ki-67 Acanthotic, cystic and follicular types of ameloblastoma,

Table 1. Summary of clinico-pathologic finding of the studied cases.

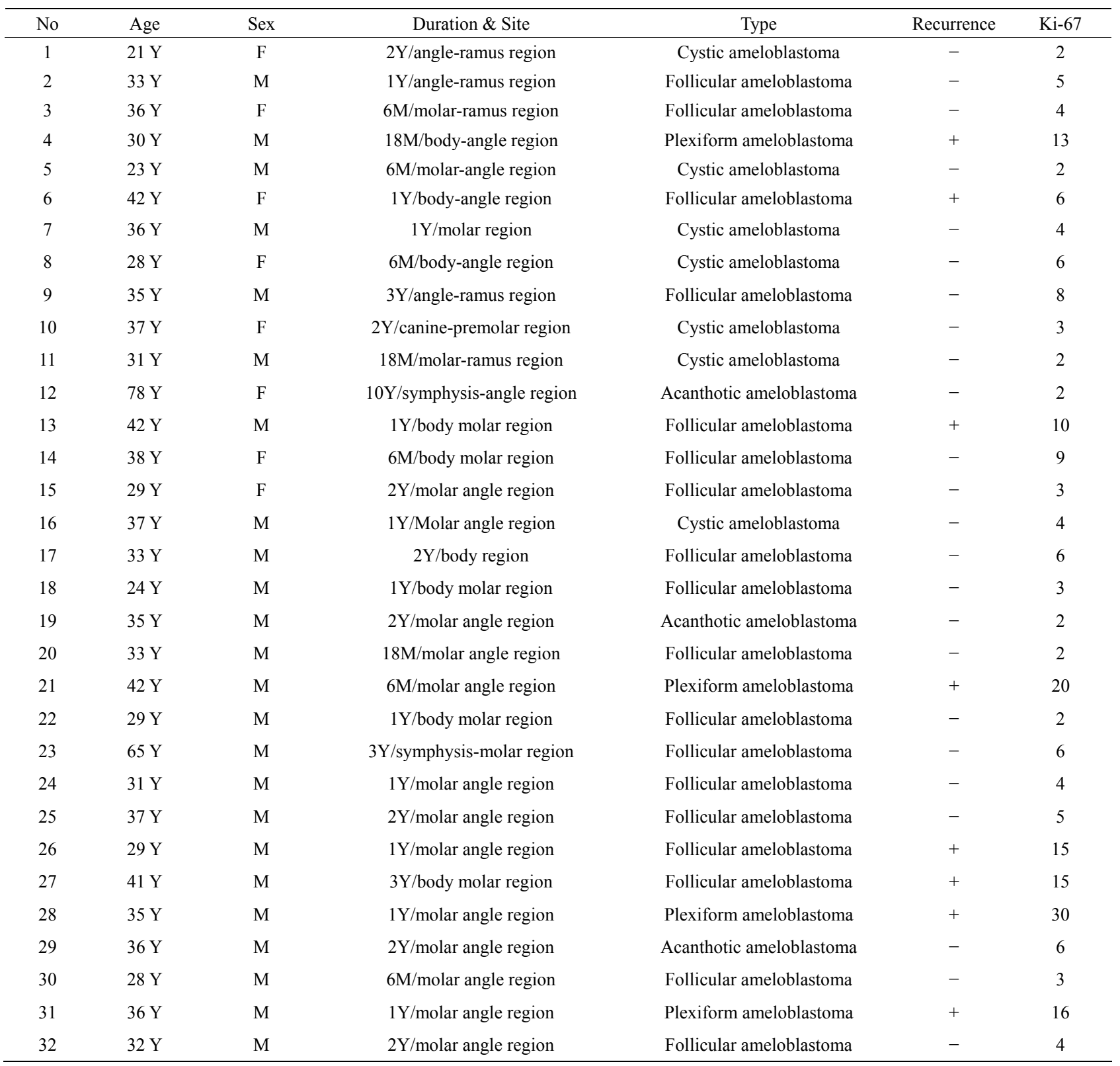


while plexiform type showed statistically significantly higher levels than the other 3 types (Figure 1). The mean Ki-67 labelling index (LI) of plexiform ameloblastoma ranged from 13 to 30 with mean of 19.75 (Table 2 and Figure 2).

Statistical analysis of the Ki-67 between the recurrent and non-recurrent cases showed that, the mean values of Ki-67 was statistically significantly higher in recurrent than non-recurrent cases (Table 3 and Figure 3).

\section{DISCUSSION}

Ameloblastoma have been categorized broadly into 3 biologic variants: cystic (unicystic), solid, and peripheral.

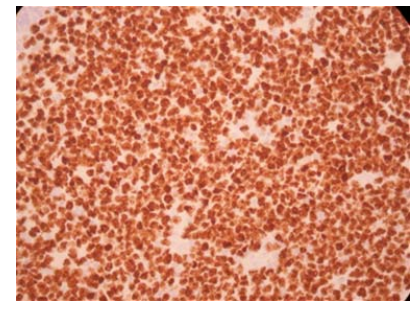

(a)

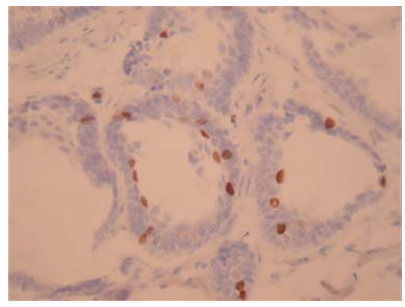

(c)

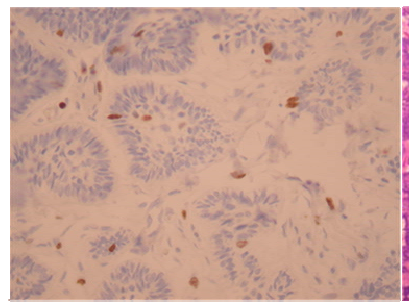

(e)

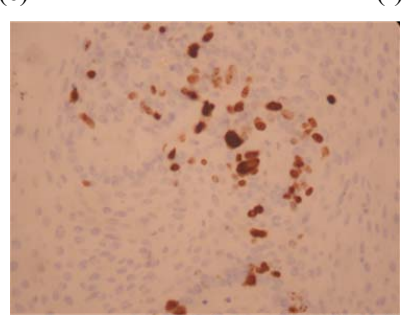

(g)

Figure 1. (a) Lymphnode germinal center (Lymphoma $\times 400)$ Ki-67 as a positive control; (b) Acanthotic ameloblastoma (H\& E); (c) Acanthotic ameloblastoma $(\times 400), \mathrm{Ki}-67$ labeling index reaching 6\%; (d) Follicular ameloblastoma (H\&E); (e) Follicular ameloblastoma Ki-67 labeling index reaching 8\%; (f) Plexiform ameloblastoma (H\&E); (g) Plexiform ameloblastoma $(\times 400)$ Ki-67 labeling index reaching $20 \%$.
Table 2. Ki-67 means levels in ameloblastoma different types.

\begin{tabular}{ccc}
\hline & Mean & St Dev \\
\hline Acanthotic & 3.33 & 2.31 \\
Cystic & 3.29 & 1.50 \\
Follicular & 6.11 & 3.94 \\
Plexiform & 19.75 & 7.41 \\
\hline
\end{tabular}

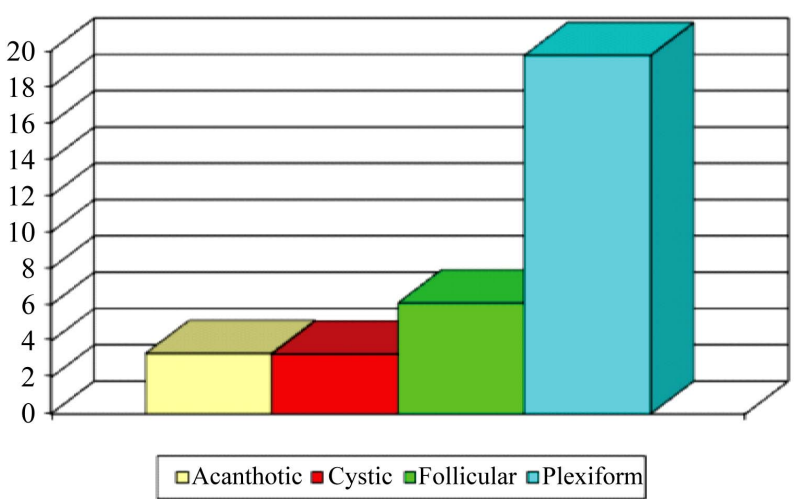

Figure 2. Plexiform type showed statistically significantly higher levels than the other 3 types.

Table 3. Independent " $t$ " test results comparing Ki-67 levels in recurrent and non-recurrent cases.

\begin{tabular}{cccc}
\hline \multicolumn{4}{c}{ Mean \pm St Dev } \\
Non-recurrent & Recurrent & "t" value & Probability \\
\hline $4.042 \pm 1.99$ & $15.63 \pm 7.15$ & 7.336 & $3.6 \mathrm{E}-08$ \\
\hline
\end{tabular}

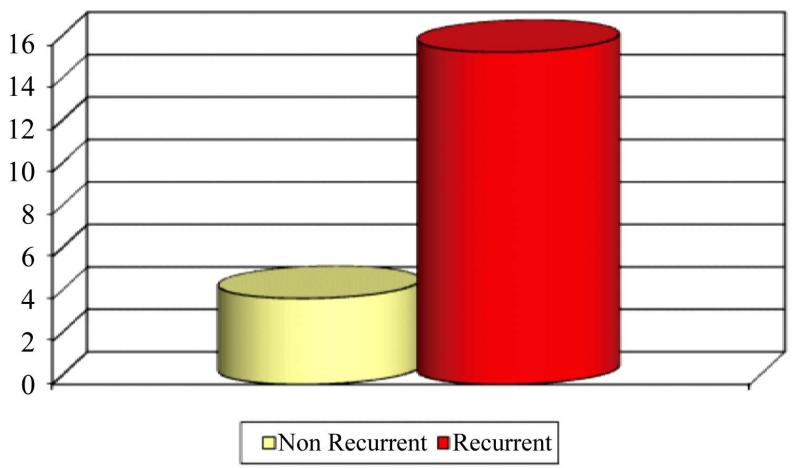

Figure 3. The mean values of Ki-67 was statistically significantly higher in recurrent than non-recurrent cases.

The literature indicates that the cystic variant is biologically less aggressive and has a better response to enucleation or curettage than does the solid ameloblastoma [18, 19].

The clinical course in any given patient with an ameloblastoma is difficult to predict because there are few features to aid the evaluation of the biological behavior of the tumor. There is no clear evidence that histologic features of ameloblastoma, such as follicular or plexiform 
patterns, determine the degree of invasiveness of individual cases or allow prediction of likelihood of recurrence or malignant transformation [20]. The only prognostically significant histologic factor is that unicystic types are less aggressive especially if associated with impacted molar teeth. Therefore, there is a need for a predictive marker of clinical behavior inameloblastoma.

The proliferative activity of tumor cells has been found to be an indicator of aggressiveness and to provide useful prognostic in formation. Immunohistochemical detection of the Ki-67antigen has provided a means of evaluating turnout cell proliferation in a range of malignancies including carcinomas of the breast and the head and neck [21-24].

Many investigations of tumor cell proliferative activity have used PCNA and Ki-67 in oral and other systemic tumors. However, despite the years of intense research on these relatively simple immunostaining techniques and the routine use of such investigations in certain malignancies such as lymphomas, the routine application of PCNA and Ki-67 in diagnostic histopathology of oral tumors is as yet of little value [25].

$\mathrm{Ki}-67$ antigen is a more specific marker of proliferating cells, maximally expressed during $\mathrm{S}$ phase, which is rapidly degraded after mitosis. The original antibody raised against this $395 \mathrm{KD} \mathrm{Ki}-67$ protein (pKi-67) is referred to as Ki-67 antibody, a prototype for other antibodies that also identify epitopes of pKi67, e.g., MIB-1 [26]. MIB-1 is an antibody that detects $\mathrm{Ki}-67$ antigenin formalin-fixed, paraffin-embedded tissue after antigen retrieval [27]. Ki67 is a nonhistone protein initially expressed in mid G1, increasing in level through S and G2 and peaking in M.

It has been suggested that Ki-67 staining is more accurate than the counting of mitoses or PCNA staining. Its estimated half-life is 60 to 90 minutes [26]. However, not all cells containing the Ki-67 antigen are actively proliferating cells, and the use of $\mathrm{Ki}-67$ to assess proliferative activity is not advised in tissues over expressing p53 or p21 [28]. It should further be noted that correlation between mitotic and Ki-67 labeling indices is variable [2934].

The Ki-67 labelling index was found to be prognostically relevant in several studies [16,17]. More recent studies using MIB1 paraffin antibody have confirmed its prognostic value $[35,36]$.

The results of the current study showed that; cellularproliferative activity as assessed by Ki-67 labeling indices varied within recurrent and non-recurrent cases of ameloblastoma. There was a significant relation between labeling index of nuclear proliferation marker Ki-67 and recurrence of ameloblastoma. Also; recurrence rate was highly significant in the plexiform ameloblastoma (100\%) which associated with the highest Ki-67 labelling index followed by Follicular ameloblastoma (22\%).
The result of Immunohistochemical data in the current study indicated that the immuno expression of Ki-67 labeling index might be a good prognostic indicator for proliferative activity and the local recurrence of mandibular ameloblastoma. The use of Ki-67 before surgical excision of the ameloblastoma can be considered as an important step in the treatment plan for evaluation of the proliferative activity and subsequent the possibility of the recurrence.

Even though, our results showed that both plexiform and follicular types expressed the higher proliferative activity and recurrence rate, but this cannot be considered as a role because of small sample size of our study. Histologic types with high Ki-67 label index should be treated with large safety margin to decrease the incidence of recurrence.

\section{CONCLUSION}

The significant expression of Ki-67 could provide useful prognostic markers for proliferative activity and good prognostic indicators for recurrence rate of mandibular ameloblastoma. Preoperative immunohistochemistry with Ki-67 could be considered as an important step for the treatment plan. Further studies on large sample size should be considered.

\section{REFERENCES}

[1] Barnes, L., Eveson, J.W., Reichart, P. and Sidransky, D., (2005) World Health Organization classification of tumours: Pathology and genetics head and neck tumours. International Agency for Research on Cancer Press, Lyon.

[2] Kramer, I.R.H.P.J. and Shear, M. (1992) Histological typing of odontogenic tumours. 2nd Edition, SpringerVerlag, Berlin, 11-14. http://dx.doi.org/10.1007/978-3-662-02858-2 3

[3] Li, T.J., Wu, Y.T., Yu, S.F. and Yu, G.Y. (2000) Unicystic ameloblastoma: A clinicopathologic study of 33 Chinese patients. American Journal of Surgical Pathology, 24, 1385-1392. http://dx.doi.org/10.1097/00000478-200010000-00008

[4] Gardner, D.G. (1996) Some current concepts on the pathology of ameloblastomas. Oral Surgery, Oral Medicine, Oral Pathology, Oral Radiology and Endodontology, 82, 660-669. http://dx.doi.org/10.1016/S1079-2104(96)80441-0

[5] Li, T.-J., Browne, R.M. and Matthews, J.B. (1995) Expression of proliferating cell nuclear antigen (PCNA) and Ki-67 in unicystic ameloblastoma. Histopathology, 26, 219-228.

http://dx.doi.org/10.1111/j.1365-2559.1995.tb01435.x

[6] Slootweg, P.J. (1995) p53 protein and Ki-67 reactivity in epithelial odontogenic lesions: An immunohistochemical study. Journal of Oral Pathology \& Medicine, 24, 393- 
397. http://dx.doi.org/10.1111/j.1600-0714.1995.tb01207.x

[7] Tilakaratne, W., Odell, E., Lock, C., Morgan, P. (1999) Cell proliferation in odontogenic tumors [abstract]. Oral Surgery, Oral Medicine, Oral Pathology, Oral Radiology and Endodontology, 88, 210.

[8] Tsai, S.T. and Jin, Y.T. (1995) Proliferating cell nuclear antigen (PCNA) expression in oral squamous cell carcinomas. Journal of Oral Pathology \& Medicine, 24, 313315.

http://dx.doi.org/10.1111/j.1600-0714.1995.tb01191.x

[9] Van Diest, P.J., Brugal, G., Baak, J.P.A. (1998) Proliferation markers in tumours: Interpretation and clinical value. Journal of Clinical Pathology, 51, 716-724. http://dx.doi.org/10.1136/jcp.51.10.716

[10] Gerdes, J., Becker, M.H.G., Key G, et al. (1992) Immunohistological detection of tumour growth fraction (Ki-67 antigen) in formalin-fixed and routinely processed tissues [letter]. Journal of Pathology, 174, 1685-1687.

[11] Guillaud, P., de Manoir, S. and Geigneurin, D. (1989) Quantification and topographical description of Ki-67 antibody labelling during the cell cycle of normal fibroblastic (MRC-5) and mammary tumour cell lines (MCF-7). Analytical Cellular Pathology, 1, 25-39.

[12] di Vinci, A., Geido, E., Pfeffer, U., et al. (1993) Quantitative analysis of mitotic and early-G1 cells using monoclonal antibodies against the AF-2 protein. Cytometry, 14, 421-427. http://dx.doi.org/10.1002/cyto.990140411

[13] Isola, J.J., Helin, H.J., Helle, M.J., et al. (1990) Evaluation of cell proliferation in breast carcinoma. Comparison of Ki-67 immunohistochemical study, DNA flow cytometric analysis, and mitotic count. Cancer, 65, 11801184 .

http://dx.doi.org/10.1002/1097-0142(19900301)65:5<118 0::AID-CNCR2820650525>3.0.CO;2-7

[14] Barnard, N.J., Hall, P.A., Lemoine, N.R., et al. (1987) Proliferative index in breast carcinoma determined in situ by Ki67 immunostaining and its relationship to clinical and pathological variables. Journal of Pathology, 152, 287-295.

[15] Gerdes, J., Becker, M.H.G., Key, G., et al. (1992) Immunohistological detection of tumour growth fraction (Ki-67 antigen) in formalin-fixed and routinely processed tissues [letter]. Journal of Pathology, 174, 1685-1687.

[16] Wintzer, H.O., Zipfel, I., Schulte-Moenting, J., et al. (1991) Ki67 immunostaining in human breast tumors and its relationship to prognosis. Cancer, 67, 421-428. http://dx.doi.org/10.1002/1097-0142(19910115)67:2<421 :AID-CNCR2820670217>3.0.CO;2-Q

[17] Veronese, S.M., Gambacorta, M., Gottardi, O., et al. (1993) Proliferation index as a prognostic marker in breast cancer. Cancer, 71, 3926-3931. http://dx.doi.org/10.1002/1097-0142(19930615)71:12<39 26::AID-CNCR2820711221>3.0.CO;2-2

[18] Robinson, L. and Martinez, M.G. (1977) Unicystic ameloblastoma: A prognostically distinct entity. Cancer, 40, 2278.

http://dx.doi.org/10.1002/1097-0142(197711)40:5<2278:: AID-CNCR2820400539>3.0.CO;2-L
[19] Philipsen, H.P. and Reichert, P.A. (1998) Unicystic ameloblastoma. A review of 193 cases from the literature. Oral Oncology, 34, 317. http://dx.doi.org/10.1016/S1368-8375(98)00012-8

[20] Gardner, D.G. and Pecak, A.M. (1980) The treatment of ameloblastoma based on pathologic and anatomic princeples. Cancer, 46, 2514-2519.

http://dx.doi.org/10.1002/1097-0142(19801201)46:11<25 14::AID-CNCR2820461133>3.0.CO;2-9

[21] Blazi, M., Ninu, B.M., Becciolin1, A., et al. (1991) Labelling index in squamous cell carcinoma of the larynx. Head \& Neck, 13, 344-348. http://dx.doi.org/10.1002/hed.2880130413

[22] Bouzubar, N., Walker, K.J., Griffith, K., et al. (1989) $\mathrm{Ki}-67$ immunostaining in primary breast cancer; pathological and clinical associations. British Journal of Cancer, 59, 943-945. http://dx.doi.org/10.1038/bjc.1989.200

[23] Brown, D.C. and Gatter, K.C (1990) Monoclonal antibody Ki-67: its use in histopathology. Histopathology, 17, 489-503.

http://dx.doi.org/10.1111/j.1365-2559.1990.tb00788.x

[24] Chaurel, P., Courdi, A., Gioanni, J., Vallicion, J., Santini, J. and Demard, E. (1989) The labelling index: A prognostic factor in head and neck carcinoma. Radiotherapy \& Oncology, 14, 231-237. http://dx.doi.org/10.1016/0167-8140(89)90171-0

[25] Brown, D.C. and Gatter, K.C. (1990) Monoclonal antibody Ki-67: Its use in histopathology. Histopathology, 17, 489-503.

http://dx.doi.org/10.1111/j.1365-2559.1990.tb00788.x

[26] Brown, D.C. and Gatter, K.C. (2002) Ki67 protein: The immaculate deception? Histopathology, 40, 2-11. http://dx.doi.org/10.1046/j.1365-2559.2002.01343.x

[27] Li, T.-J., Browne, R.M. and Matthews, J.B. (1995) Expression of proliferating cell nuclear antigen (PCNA) and Ki-67 in unicystic ameloblastoma. Histopathology, 26, 219-228. http://dx.doi.org/10.1111/j.1365-2559.1995.tb01435.x

[28] Van Oijen, M.G.C.T., Medema, R.H., Slootweg, P.J. and Rijksen, G. (1998) Positivity of the proliferation marker Ki-67 in noncycling cells. American Journal of Clinical Pathology, 110, 24-31.

[29] Rudolph, P., Peters, J., Lorenz, D., Schmidt, D. and Parwaresch, R. (1998) Correlation between mitotic and Ki67 labeling indices in paraffin-embedded carcinoma specimens. Human Pathology, 29, 1216-1222. http://dx.doi.org/10.1016/S0046-8177(98)90248-9

[30] Li, Y., Han, B. and Li, L.-J. (2012) Prognostic and proliferative evaluation of ameloblastoma based on radiographic boundary. International Journal of Oral Science, 4, 30-33. http://dx.doi.org/10.1038/ijos.2012.8

[31] Florescu, A., Simionescu, C., Ciurea, R. and Pitru, A. (2012) P53, Bcl-2 and Ki67 immunoexpression infollicular solid ameloblastomas. Romanian Journal of Morphology and Embryology, 53, 105-109.

[32] Kumamoto, H., Izutsu, T., Ohki, K., Takahashi, N. and Ooya, K. (2004) p53 gene status and expression of p53, MDM2, and p14 proteins in ameloblastomas. Journal of 
Oral Pathology \& Medicine, 33, 292-299. http://dx.doi.org/10.1111/j.0904-2512.2004.00044.x

[33] Gadbail, A.R., Patil, R. and Chaudhary, M. (2012) Coexpression of Ki-67and p53 protein in ameloblastoma and keratocysticodontogenic tumor. Acta Odontologica Scandinavica, 70, pp. 529-535.

[34] de Vicente, J.C., Torre-Iturraspe, A., Gutiérrez, A.M. and Lequerica-Fernández, P. (2010) Immunohistochemical comparative study of the odontogenic keratocysts and other odontogenic lesions. Medicina Oral Patologia Oral y Cirugia Bucal, 15, e709-e715.

http://dx.doi.org/10.4317/medoral.15.e709
[35] Pietilainen, T., Lipponen, P., Aaltomaa, S., et al. (1996) The important prognostic value of Ki-67 expression as determined by image analysis in breast cancer. Journal of Cancer Research and Clinical Oncology, 122, 687-692. http://dx.doi.org/10.1007/BF01209033

[36] Pinder, S.E., Wencyk, P., Sibbering, D.M., et al. (1995) Assessment of the new proliferation marker MIB1 in breast carcinoma using image analysis: Associations with other prognostic factors and survival. British Journal of Cancer, 71, 1546-1549.

http://dx.doi.org/10.1038/bjc.1995.30 